\title{
Effect of tertiary amines on yellowing of UV-curable epoxide resins
}

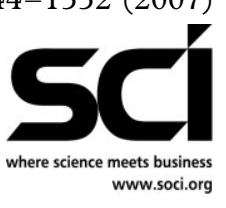

\author{
Tzu Hsuan Chiang and Tsung-Eong Hsieh* \\ Department of Materials Science and Engineering, National Chiao Tung University, 1001 Ta-Hsueh Road, Hsinchu, Taiwan 30010, ROC
}

\begin{abstract}
The work reported demonstrates that the yellowness of UV-curable epoxide resins can be improved by adding certain tertiary amines in appropriately determined amounts. According to the results of our experiments, $2.0 \mathrm{wt} \%$ benzoyl peroxide added to a resin effectively enhances the crosslinking density, and phenolic free radicals are produced during UV curing, which consequently induce yellowness via the reaction of oxygen and the free radicals. Imidazole (1-amine) and tertiary amines, including 1,2-dimethylimidazole (2-amine), 2,4,6tris(dimethylaminomethyl)phenol (3-amine), 1-methylimidazole (4-amine) and 2-methylimidazole (5-amine), were chosen to be added to resins, and their effects on UV conversion and yellowness were investigated. According to the experimental results, tertiary amines in the resin can provide a certain degree of improvement in yellowness index $(\Delta Y I)$ and color parameter $\left(\Delta E^{*}{ }_{a b}\right)$ of the resin sample. Whatever the type of tertiary amine, it is found that the optimum content of amine in resin is $1.0 \mathrm{wt} \%$. Also, among the studied amines, the 3-amine exhibits the highest UV reactivity and the best efficiency for yellowness improvement with values of $\Delta a^{*}, \Delta b^{*}, \Delta Y I$ and $\Delta E^{*}{ }_{a b}$ as low as $-1.4,6.23,11.27$ and 6.48 , respectively.
\end{abstract}

(C) 2007 Society of Chemical Industry

Keywords: tertiary amines; yellowness; UV-curable epoxide resin

\section{INTRODUCTION}

There are many applications of UV-curable epoxide resins in the electronic and optoelectronic industries due to their fast polymerization rate and good physical properties. UV-curable resins are specifically required in the packaging of advanced flat-panel displays (FPDs), e.g. organic light-emitting devices (OLEDs), for the light-emitting materials in these devices cannot tolerate high-temperature thermal processes. ${ }^{1}$ Encapsulation of devices must be achieved over the whole light-emitting area so that transparency becomes an important issue for sealing resins, ${ }^{2,3}$ as the developing trend switches from conventional bottomemitting OLEDs to top-emitting OLEDs (TOLEDs) and flexible OLEDs (FOLEDs). Yellowing is a common detriment to the transparency of UVcurable resins because of their poor resistance to subsequent UV exposure. Yellowness of UV-curable resins may be caused by: (i) photo-yellowing reactions which are induced by residual photo-initiators; ${ }^{4-6}$ (ii) hydrogen atoms being abstracted by the residual photo-initiator; $^{7}$ (iii) oxidization due to the presence of functional groups containing residual free radicals in resins; ${ }^{8}$ and (iv) hydroperoxidation resulting from the formation of conjugated unsaturated carbonyl products with strong UV absorption at a wavelength of $275 \mathrm{~nm} .^{9}$

Triarylsulfonium salts are used as photo-initiators for their high thermal stability, but they undergo rapid photolysis when irradiated by UV light with wavelengths ranging from 200 to $300 \mathrm{~nm}$. Both homolytic and heterolytic cleavage mechanisms are involved in the photolysis of triarylsulfonium salt photo-initiators. In the homolytic process, the excited state first cleaves to release diphenylsulfinyl radical cation, phenyl radical and anion. Equation (1) depicts the reactive species including aryl radicals, aryl cationic radicals, aryl cations and Brønsted acid $\left(\mathrm{H}^{+} \mathrm{SbF}_{6}{ }^{-}\right)$generated by the photolysis of the photoinitiator: ${ }^{10,11}$

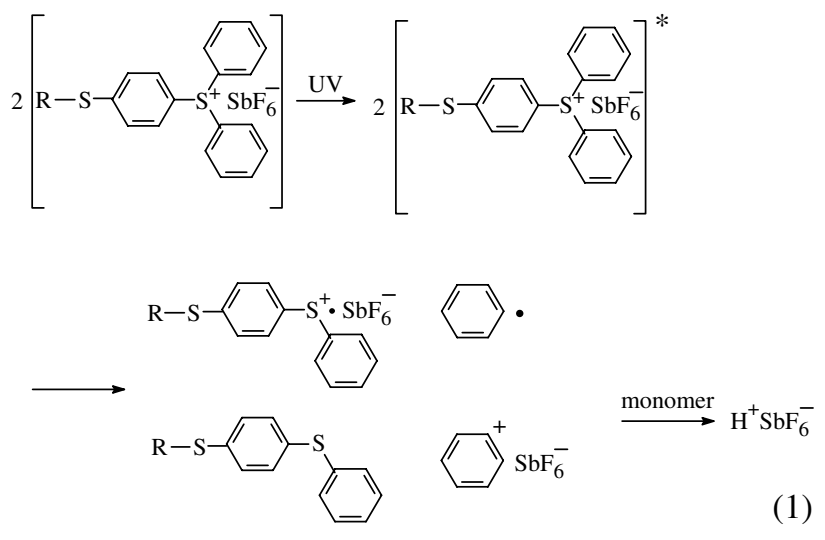

The yellowness of resin samples results from the residual free radicals that are generated by photosensitizing sulfonium salt photo-initiator (Eqn (1)), polymer and photosensitizer. The radicals react with oxygen in air to produce free radicals via the oxidation reaction shown in Eqn (2). ${ }^{12}$ As depicted by

\footnotetext{
* Correspondence to: Tsung-Eong Hsieh, Department of Materials Science and Engineering, National Chiao Tung University, 1001 Ta-Hsueh Road, Hsinchu, Taiwan 30010, ROC

E-mail: cjjiang@ms.chinmin.edu.tw; tehsieh@cc.nctu.edu.tw

Contract/grant sponsor: Ministry of Education of the Republic of China; contract/grant number: 91-E-FA04-2-4

(Received 21 November 2006; revised version received 11 February 2007; accepted 27 February 2007)

Published online 8 June 2007; DOI: 10.1002/pi.2300 
Eqns (3) and (4), the free radicals further react with polymer $(\mathrm{RH})$ and other free radicals or phenolic radicals to form hydroperoxide ( $\mathrm{ROOH})$ or ester, respectively. It is known that the presence of hydroperoxide induces the yellowing of resins. ${ }^{13-15} \mathrm{ROOH}$ is then decomposed to alkoxy and hydroxide radicals in accordance with Eqn (5) ${ }^{16,17}$ and subsequently reacts with $\mathrm{RH}$ to form alkyl radical (Eqn. (6)) and the alkyl radicals are formed by the continuous repetition of reactions shown in Eqns (2)-(7). The more residual free radicals generated in the resin samples, the more hydroperoxides will be produced and the more severe will be the yellowing in the UV-curable epoxide resins.

$$
\begin{aligned}
\mathrm{R}^{\bullet}+\mathrm{O}_{2} & \longrightarrow \mathrm{ROO}^{\bullet} \\
\mathrm{ROO}^{\bullet}+\mathrm{RH} & \longrightarrow \mathrm{ROOH}+\mathrm{R}^{\bullet} \\
\mathrm{ROO}^{\bullet}+\mathrm{R}^{\bullet} & \longrightarrow \mathrm{ROOR}^{\circ} \\
\mathrm{ROOH} & \longrightarrow \mathrm{RO}^{\bullet}+\mathrm{OH}^{\bullet} \\
\mathrm{RO}^{\bullet}+\mathrm{RH} & \longrightarrow \mathrm{ROH}+\mathrm{R}^{\bullet} \\
\mathrm{OH}^{\bullet}+\mathrm{RH} & \longrightarrow \mathrm{R}^{\bullet}+\mathrm{H}_{2} \mathrm{O}
\end{aligned}
$$

The yellowness of UV-curable resins can be improved by adding light stabilizers which consist of UV absorbers and radical scavengers. One of the specific features of tertiary amines is they may react with carbonyl compounds, singlet oxygen and other species via an electron-transfer process to improve the low ionization potential property. ${ }^{18}$ Normally, amine retards cationic photopolymerization. But some amines, such as mono-acrylate of a cyclic carbamate, mono-acrylate of a cyclic urethane ${ }^{18}$ and amine acrylate, ${ }^{19,20}$ may also serve as oxygen inhibitors that can reduce the yellowness of UV-curable resins. Imidazole usually serves as a thermal accelerator and can be thermally cured at $80-120^{\circ} \mathrm{C}$. It not only reacts with epoxy through one or both of the nitrogens on the ring but also catalyzes the reactions. Thermal polymerization of imidazole and other tertiary amines has been widely studied, ${ }^{21-24}$ but the addition of tertiary amines to UV-curable resins and their effects on key physical properties are rarely reported.

Chemical grafting and addition of tertiary amines which serve as oxygen inhibitors to retard the yellowing of UV-curable epoxide resins were investigated in the work reported in the present paper. The effects of amine type and content on UV conversion and yellowness of resin samples were studied. The type of tertiary amine and optimum content were identified, which allow fabrication of a UV-curable epoxide resin with properties satisfactory for packaging applications of advanced FPD products.

\section{EXPERIMENTAL}

\section{Materials and sample preparation}

The 3,4-epoxycyclohexylmethyl 3,4-epoxycyclohexanecarboxylate epoxide oligomer resin, the triarylsulfonium hexafluoroantimonate salt photo-initiator, the monomer and tri(propylene glycol) were all purchased from Aldrich Co. The benzoyl peroxide (BPO) thermal initiator was provided by Fluka Co. The chemical structures, designated names and providers of the five tertiary amines under study are listed in Table 1.

The processes to prepare resin samples were as follows. First, the base matrix for each sample preparation was mixed with the cycloaliphatic epoxide and monomer at a weight ratio of $4: 1$ for $1.5 \mathrm{~h}$ and stirred. Then different amounts of BPO and about $1.5 \mathrm{~g}$ of photo-initiator for each sample was placed in the mixture, followed by another $1.5 \mathrm{~h}$ of stirring. The optimum BPO content was determined via a UV conversion experiment, and various types and amounts of tertiary amine were added to the above resin mixture with specific BPO contents and stirred to complete the resin sample preparation. For subsequent analyses, the resin samples were coated on glass plates and cured in a UV oven (C-SUN, UC-1000) for various times followed by post-baking at various temperatures for $1 \mathrm{~h}$. The thickness of thin-film samples was about $130 \pm 2 \mu \mathrm{m}$.

\section{Property characterization}

\section{UV conversion}

The samples for UV conversion were prepared by coating the resin samples on $\mathrm{KBr}$ disks, which were then cured in the UV oven for various times. The samples were then analyzed using a Fourier transform infrared (FTIR) spectrometer (Nicolet Protégé 460 FTIR) for structure characterization. The conversions of samples were determined from the absorbance intensity of peaks at $910 \mathrm{~cm}^{-1}$ in the FTIR spectra. An internal standard band method was adopted by choosing the absorption band at $1728 \mathrm{~cm}^{-1}$ of $\mathrm{C}=\mathrm{O}$ of dicycloaliphatic epoxide as an internal standard band for conversion calculation in order to compensate for the change in sample thickness resulting from UV curing. The conversions of samples were calculated according to the following equation:

$$
\mathrm{UV} \text { conversion }(\%)=\left(1-\frac{[A]_{\mathrm{E} t} /[A]_{\mathrm{r} t}}{[A]_{\mathrm{E} 0} /[A]_{\mathrm{r} 0}}\right) \times 100
$$

where $[A]_{\mathrm{Et}}=$ peak intensity of epoxy group in the normalized spectrum of the sample subjected to UV curing, $[A]_{\mathrm{r} t}=$ peak intensity of $\mathrm{C}=\mathrm{O}$ group in the normalized spectrum of the sample subjected to UV curing, $[A]_{\mathrm{E} 0}=$ peak intensity of epoxy group in the normalized spectrum of the sample prior to UV curing and $[A]_{\mathrm{r} 0}=$ peak intensity of $\mathrm{C}=\mathrm{O}$ group in the normalized spectrum of the sample prior to UV curing.

\section{NMR characterization}

Each of tertiary amines was blended with BPO, and then all samples were cured by UV radiation and further dissolved in $\mathrm{CDCl}_{3}$ and characterized from their ${ }^{1} \mathrm{H}$ NMR spectra recorded using an INOVA $500 \mathrm{MHz}$ NMR spectrometer. 
Table 1. Chemical structures and designated names of tertiary amines

\begin{tabular}{|c|c|c|c|}
\hline Tertiary amine & Chemical structure & Designated name & Supplier \\
\hline Imidazole & $\mathrm{H}$ & 1-amine & Aldrich \\
\hline 1,2-Dimethylimidazole & $\mathrm{CH}_{3}$ & 2-amine & Aldrich \\
\hline 2,4,6-Tris(dimethylaminomethyl)phenol & ars & 3-amine & $\mathrm{TCl}$ \\
\hline 1-Methylimidazole & $\mathrm{CH}_{3}$ & 4-amine & Aldrich \\
\hline 2-Methylimidazole & & 5-amine & Aldrich \\
\hline
\end{tabular}

\section{Transmittance}

An Agilent 8453 UV-visible spectrometer was utilized to measure the transmittances of resin samples which were coated on a glass substrate and subjected to UV and post-baking treatments.

\section{Yellowness indices and color parameters}

The yellowness of specimens was evaluated in accordance with the standard ASTM E313-05 using a spectrophotometer (Minolta, CM-508i) in conjunction with the On Color software (Version 5.3.0.7 QC-Basic, Cyber Chrome, Inc.). First, the reflectance of a sample was measured in the visible region with wavelengths ranging from 400 to $700 \mathrm{~nm}$. Reflectance data were taken from a $20 \mathrm{~nm}$ wavelength interval on an $8 \mathrm{~mm}^{2}$ area of specimen and a white color standard (i.e. double A white paper). The CIE values, Commission International d'Eclairage standard, ${ }^{25,26}$ corresponding to resin sample $\left(L^{*}, a^{*}\right.$ and $\left.b^{*}\right)$ and the white standard $\left(L^{*}{ }_{\text {std }}, a^{*}\right.$ std and $\left.b^{*}{ }_{\text {std }}\right)$ could then be calibrated. It is noted that $L^{*}$ is the value or the degree of lightness in the Munsell system, while $a^{*}$ and $b^{*}$ coordinates designate the positions on red or green $\left(+a^{*}=\right.$ red, $-a^{*}=$ green $)$ and yellow or blue $\left(+b^{*}=\right.$ yellow, $-b^{*}=$ blue $)$ axes, respectively. By utilizing these parameters, the color parameter $\left(\Delta E^{*}{ }_{a b}\right)^{27}$ and yellowness index $(\Delta \mathrm{YI})^{28}$ of the resin samples were calculated according to

$$
\Delta E_{a b}^{*}=\sqrt{\left(\Delta L^{*}\right)^{2}+\left(\Delta a^{*}\right)^{2}+\left(\Delta b^{*}\right)^{2}}
$$

and

$$
\Delta \mathrm{YI}=\frac{1.28 X-1.06 Z}{Y} \times 100
$$

where $\Delta L^{*}=L^{*}-L^{*}{ }_{\text {std }}, \Delta a^{*}=a^{*}-a^{*}{ }_{\text {std }}, \Delta b^{*}=b^{*}-$ $b^{*}$ std and $(X, Y, Z)$ are the tristimulus values calculated from the color reflectance spectra ${ }^{19}$ obtained using a $2^{\circ}$ observer.

\section{RESULTS AND DISCUSSION Effects of BPO and UV reactivity conversions on amine-free samples}

$\mathrm{BPO}$ is a common free radical photo-initiator and/or thermal initiator in UV-curable resins. The radicals for polymerization are generated via the thermal or photochemical decomposition of BPO. ${ }^{29}$ Fig. 1 presents the reactivity (conversion) of resin samples containing various amounts of $\mathrm{BPO}$, which were irradiated for $10 \mathrm{~min}$ with UV light and post-cured at $80^{\circ} \mathrm{C}$ for $1 \mathrm{~h}$, evaluated by the absorbance changes of the peaks corresponding to the epoxy group at $910 \mathrm{~cm}^{-1}$ of FTIR spectra. As the UV irradiation starts, it can be seen that the conversions of all samples dramatically increase then gradually reach a plateau when UV irradiation time exceeds about $10 \mathrm{~min}$. The increasing trend of UV conversions of the epoxy group shown in Fig. 1 also implies that the addition of BPO up to about $2.0 \mathrm{wt} \%$ benefits the photopolymerization of resins. Generally, free radicals can react with other free radicals to induce grafting, which is a homopolymerization reaction 


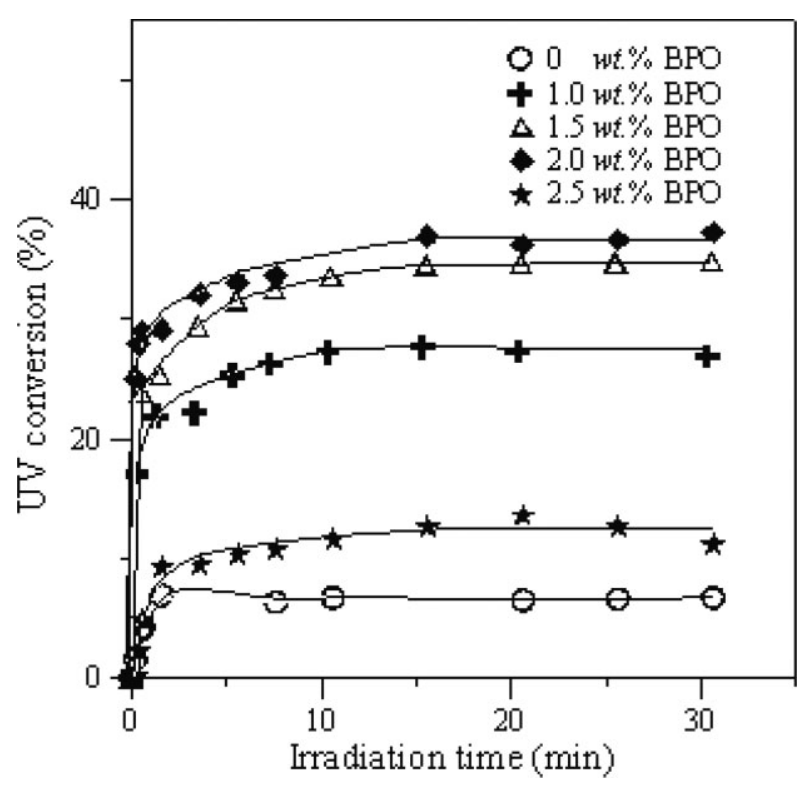

Figure 1. Conversions of resin samples evaluated by absorbance change of the peak corresponding to epoxy group at $910 \mathrm{~cm}^{-1}$ of FTIR spectra versus the UV irradiation time.

product macroradical and process termination ${ }^{30,31}$ at high conversion. But above a certain BPO content $(>2.0 \mathrm{wt} \%)$ more phenolic radicals might react with ambient oxygen to form moisture in the resins ${ }^{23}$ and consequently inhibit the UV curing. The results are intriguing since most researchers have reported that higher relative humidity resulted in lower curing conversions. ${ }^{32}$ Therefore, the resin containing $2.0 \mathrm{wt} \%$ $\mathrm{BPO}$ is adopted as the resin base for subsequent yellowing study.

\section{Effects of BPO content on yellowness of amine-free samples}

The UV-curable resins were irradiated by UV light for $10 \mathrm{~min}$ and post-cured at $80^{\circ} \mathrm{C}$ so as to study the effects of various BPO contents on yellowing. Table 2 and Fig. 2 present $\Delta E^{*}{ }_{a b}, \Delta \mathrm{YI}$ and transmittance change as a function of BPO content in tertiary amine-free resin samples. It can be seen that both $\Delta E^{*}{ }_{a b}$ and $\Delta \mathrm{YI}$ increase with increasing amount of $\mathrm{BPO}$ and the transmittance decreases with increasing BPO content within the visible-light wavelength range. Further, the values of $\Delta L^{*}$ in Table 2 define the transparency of samples: a higher $\Delta L^{*}$ value means a higher transparency. The decrease of $\Delta L^{*}$ with increasing BPO content shown in Table 2 implies

Table 2. $\Delta L^{*}, \Delta a^{*}, \Delta b^{*}, \Delta E^{*}{ }_{a b}$ and $\Delta \mathrm{YI}$ of resin samples with different BPO content

\begin{tabular}{lccccc}
\hline BPO (wt\%) & $\Delta L^{*}$ & $\Delta a^{*}$ & $\Delta b^{*}$ & $\Delta E^{*}{ }_{a b}$ & $\Delta Y \mathrm{YI}$ \\
\hline 0 & -12.27 & 2.08 & 20.95 & 24.36 & 45.84 \\
1.0 & -14.81 & 2.57 & 24.73 & 28.94 & 54.26 \\
1.5 & -16.28 & 2.88 & 26.31 & 31.19 & 59.09 \\
2.0 & -15.55 & 3.52 & 29.03 & 33.12 & 63.06 \\
2.5 & -25.09 & 8.43 & 30.13 & 40.11 & 75.94 \\
\hline
\end{tabular}

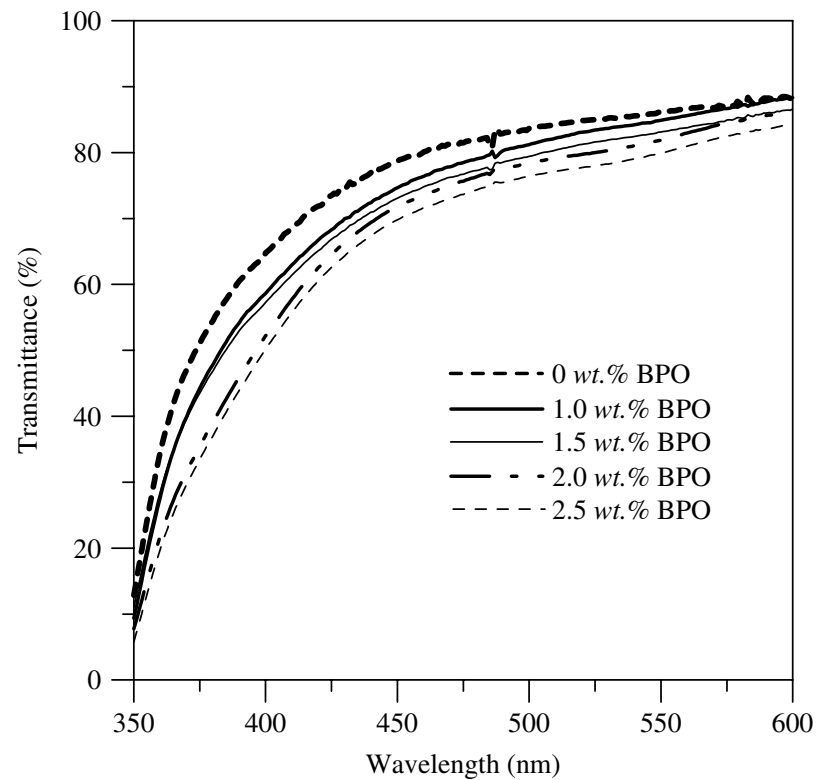

Figure 2. Transmittance changes versus BPO content of resin samples.

the degradation of transparency of resin samples with increasing BPO content as presented in Fig. 2. These results clearly indicate that addition of BPO increases the yellowing and decreases the transparency of UVcurable epoxide resins, although it did benefit the photopolymerization process. Free radicals, which are generated as BPO is heated or irradiated by UV light and follow-up induced reactions, reacted with oxygen in air to produce hydroperoxide which induces the yellowness of resins. ${ }^{9,14,15}$

\section{Effects of amine type and content on yellowness}

The resin containing $2.0 \mathrm{wt} \% \mathrm{BPO}$ was adopted as the base resin matrix since it had the highest UV conversion. Different types and amounts of tertiary amine were then added into the base resin matrices, and their effects on the yellowness were evaluated. Before the addition of amines, $\Delta E^{*}{ }_{a b}$ and $\Delta Y \mathrm{Y}$ of the base resin matrix are 33.12 and 63.06, respectively. There was substantial improvement of yellowness in all samples after the addition of tertiary amines, as seen in the summary of the results in Table 3. For all samples, the values of $\Delta E^{*}{ }_{a b}$ and $\Delta Y$ I both decrease with increasing amine content in the resin samples. The most effective is the sample containing $1.0 \mathrm{wt} \%$ of 3-amine that exhibits the lowest $\Delta E^{*}{ }_{a b}$ and $\Delta \mathrm{YI}$ of 6.48 and 11.27 , respectively. The addition of 3-amine in the resin gave the best improvement in yellowness, and thus could be attributed to its highest reactivity among all the amines studied in this work. In fact, 3amine possesses the highest functionality and certainly has the largest influence among the amines with same weight percentage.

Furthermore, as shown in Table 3, the resin containing 3-amine exhibits the highest $\Delta L^{*}$ value which implies the highest transparency. Figure 3 shows the transmittances of resin samples containing 
Table 3. $\Delta L^{*}, \Delta a^{*}, \Delta b^{*}, \Delta E^{*}{ }_{a b}$ and $\Delta \mathrm{YI}$ of resin samples containing tertiary amines

\begin{tabular}{lcccccc}
\hline $\begin{array}{l}\text { Amine } \\
\text { type }\end{array}$ & $\begin{array}{c}\text { Amount } \\
\text { (wt\%) }\end{array}$ & \multicolumn{1}{c}{$\Delta L^{*}$} & $\Delta a^{*}$ & $\Delta b^{*}$ & $\Delta E^{*}{ }_{a b}$ & $\Delta \mathrm{YI}$ \\
\hline \multirow{4}{*}{ 1-amine } & 0 & -15.55 & 3.52 & 29.03 & 33.12 & 63.06 \\
& 0.5 & -6.76 & -1.09 & 18.24 & 19.48 & 36.1 \\
& 0.8 & -4.02 & -2.2 & 11.27 & 12.2 & 21.25 \\
2-amine & 1 & -2.4 & -2.04 & 6.89 & 7.58 & 11.84 \\
& 0.5 & -6.37 & -1.4 & 17.64 & 18.81 & 34.48 \\
& 0.8 & -2.58 & -1.4 & 8.93 & 9.4 & 12.13 \\
3-amine & 0.5 & -4.73 & -1.01 & 13.6 & 14.43 & 27.1 \\
& 0.8 & -1.46 & -1.26 & 6.38 & 6.67 & 12.46 \\
& 1 & -1.12 & -1.4 & 6.23 & 6.48 & 11.27 \\
4-amine & 0.5 & -5.43 & -0.42 & 16.36 & 17.71 & 33.59 \\
& 0.8 & -1.56 & -1.77 & 7.64 & 8.04 & 16.98 \\
& 1 & -1.3 & -1.97 & 6.3 & 6.67 & 11.47 \\
5-amine & 0.5 & -17.67 & 1.3 & 23.19 & 29.18 & 49.44 \\
& 0.8 & -10.85 & -1.08 & 17.36 & 20.5 & 36.57 \\
& 1 & -2.97 & -1.84 & 11.26 & 11.79 & 21.59 \\
\hline
\end{tabular}

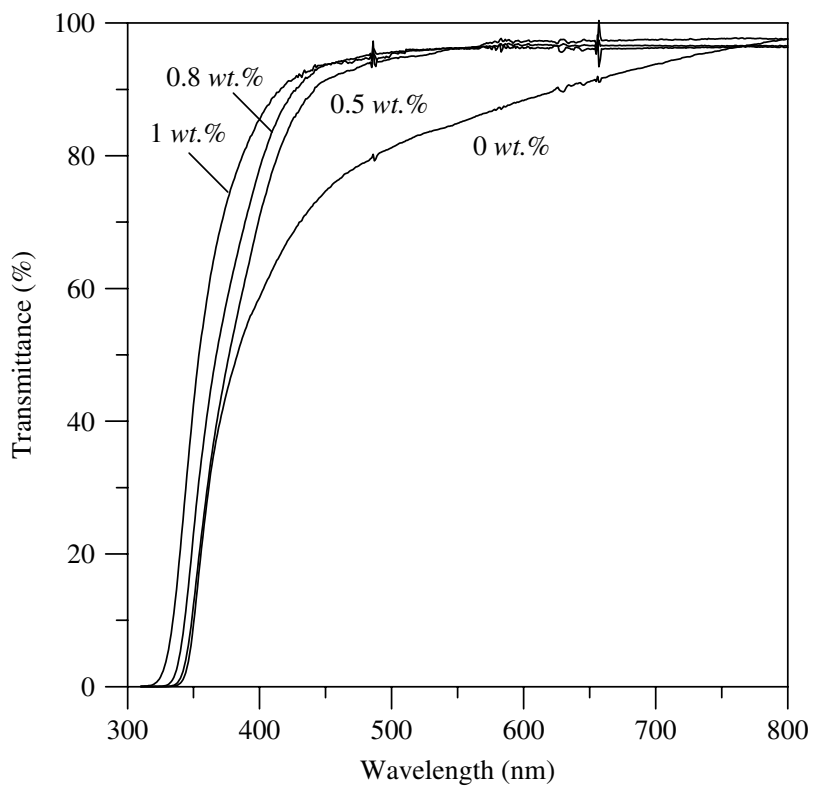

Figure 3. Transmittance of resin sample containing various amounts of 3-amine.

various amounts of 3-amine. It is noted that the variations in transmittance for different contents of amine are similar for all five types of amine studied in this work. The increasing trend of transmittance again evidences the effectiveness for improving yellowness by the addition of tertiary amine.

The individual tertiary amines of $1.0 \mathrm{wt} \%$ were mixed with $2.0 \mathrm{wt} \% \mathrm{BPO}$, and then underwent UV irradiation for $10 \mathrm{~min}$. The results of the reaction were studied by FTIR spectroscopy. The 3-amine mixed with BPO underwent UV irradiation, and the absorption intensity of $\mathrm{CH}_{3}-\mathrm{N}$-at $1232 \mathrm{~cm}^{-1}$ disappeared as shown in Fig. 4. In addition, Fig. 5 shows the ${ }^{1} \mathrm{H}$ NMR spectra of 3-amine mixed with BPO before and after UV irradiation. The $\mathrm{CH}_{3}-\mathrm{N}-$ of 3-amine demonstrated a chemical shift from 3.284 to $3.757 \mathrm{ppm}$ after UV irradiation and the same results were obtained for 2-amine and 4-amine. Figures 4 and 5 indicate that 2-amine, 3-amine and 4 -amine react with BPO under UV irradiation. These additions effectively suppress the number of free radicals and hence improve the yellowing of samples by reducing the formation of hydroperoxides. Singlet oxygen produced a triplet energy transfer from a photosensitizer (i.e. free radical initiators such as BPO) to ground-state oxygen during UV irradiation. ${ }^{33}$ The singlet oxygen may react with 2 -amine, 3-amine and 4-amine via an electron-transfer process to produce $\alpha$-aminoalkyl radicals in accordance with Eqn $(11)^{17}$ reacting with oxygen to produce $\alpha$-hydroperoxyamine $\left(\mathrm{HOOCH}_{2} \mathrm{NR}_{2}\right)$ and $\alpha$-aminoalkyl radical via the reactions shown in Eqns (12) and (13). ${ }^{11,17}$ Therefore, improvement of yellowing could be explained by the oxygen-scavenging processes of tertiary amines, as depicted by Eqns (11)-(13).

According to Fig. 6, when 1-amine was reacted with $\mathrm{BPO}$ and underwent UV irradiation, the absorption intensity of $\mathrm{NH}$-at $1136 \mathrm{~cm}^{-1}$ disappeared; the same result was obtained when 1-amine when replaced by 5 -amine. Figure 6 indicates that 1 -amine and 5 -amine react with BPO under UV irradiation, improving the yellowing of samples by reducing the formation of hydroperoxides. The aminyl radicals of 1-amine and 5amine reacting with singlet oxygen shown in Eqn (14) further react with oxygen to produce $\mathrm{HOONR}_{2}$ and aminyl radical via the reactions shown by Eqns (15) and (16). The oxygen-scavenging processes (depicted by Eqns $(14)-(16)$ ) are able to inhibit the oxidation

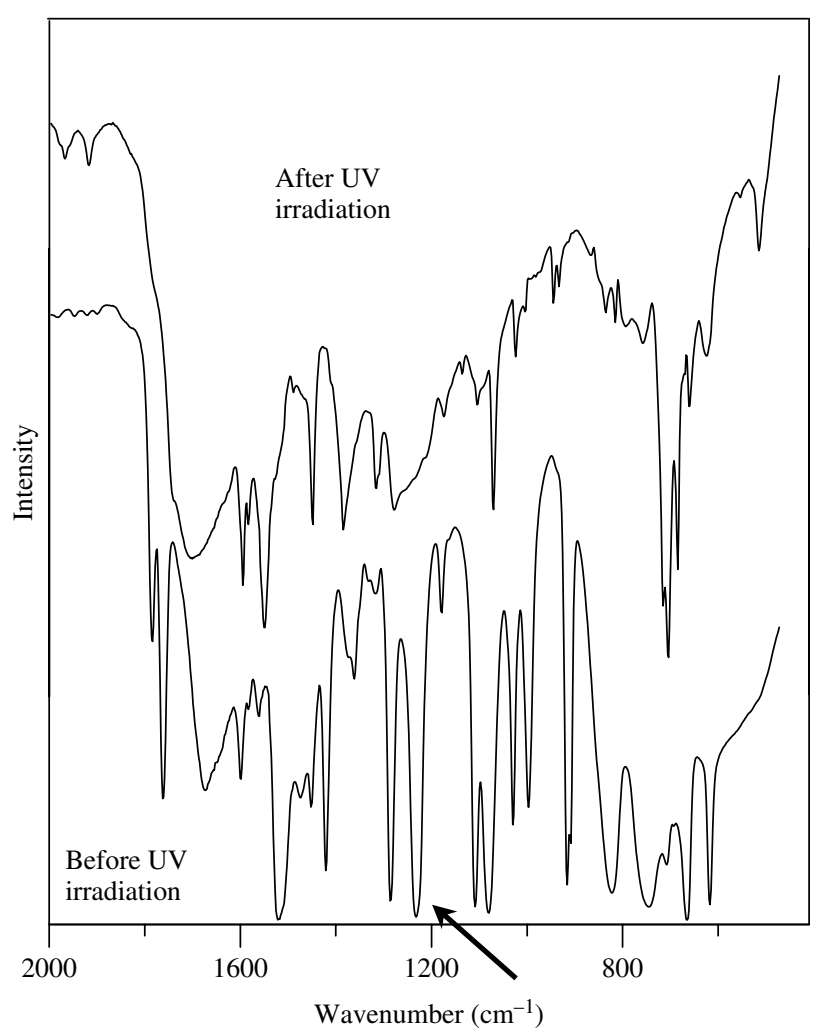

Figure 4. FTIR spectra of 3-amine mixed with BPO before and after UV irradiation. 

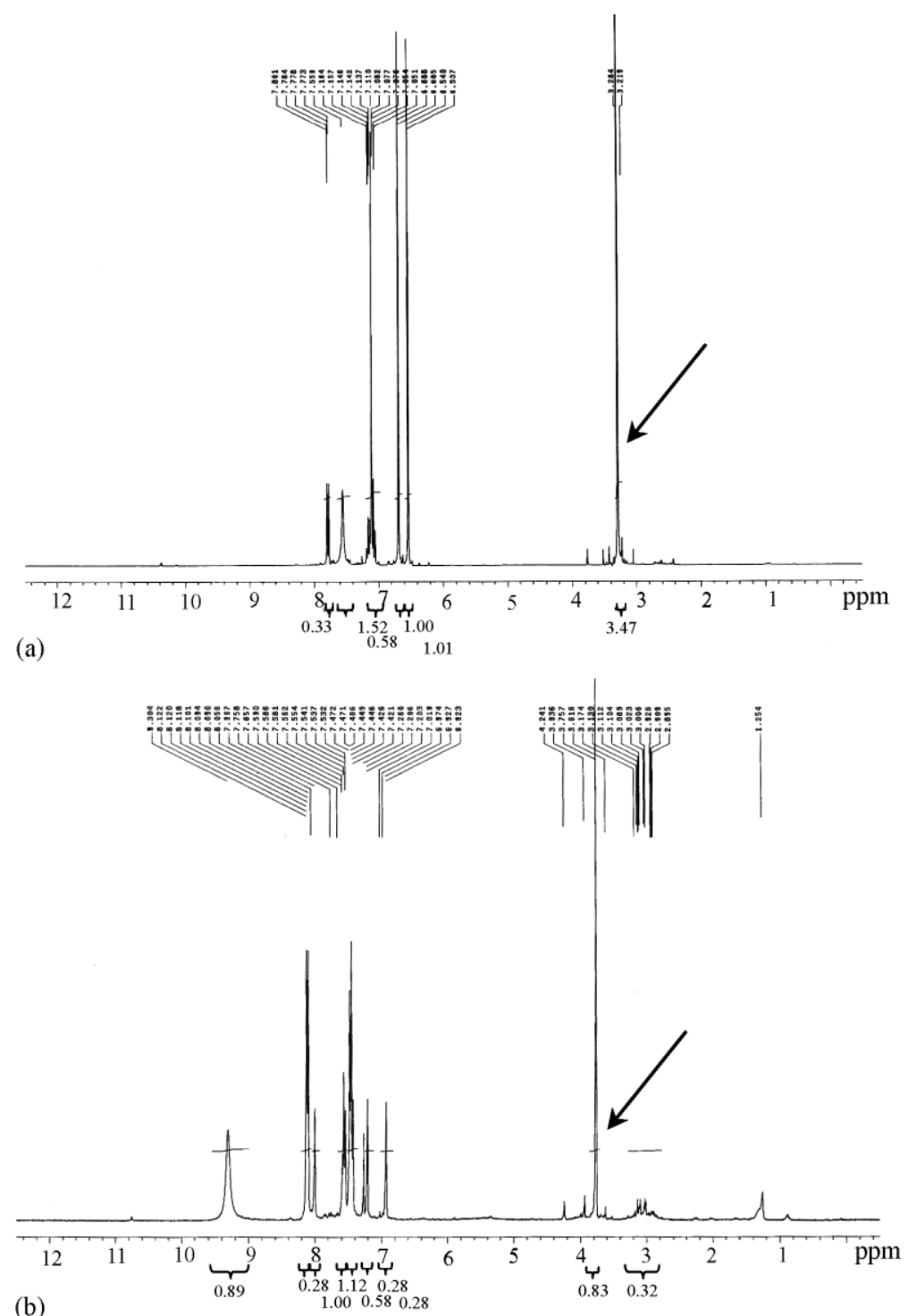

(b)

Figure 5. ${ }^{1} \mathrm{H}$ NMR spectra of 4-amine mixed with BPO (a) before UV irradiation and (b) after irradiation.

in the backbone structure of resins. ${ }^{3}$ This implies that yellowing can be effectively improved by reducing the presence of hydroperoxides in the resin samples (see Eqn (3)).

$$
\begin{aligned}
& \mathrm{CH}_{3}-\mathrm{N} \chi_{\mathrm{R}}^{\mathrm{R}}+{ }^{1} \mathrm{O}_{2} \longrightarrow \stackrel{\mathrm{CH}_{2}}{ }-\mathrm{N} \chi_{\mathrm{R}}^{\mathrm{R}}+\mathrm{HO}_{2}^{\bullet} \\
& \stackrel{\bullet}{\mathrm{C}} \mathrm{H}_{2}-\mathrm{N} \succ{ }_{\mathrm{R}}^{\mathrm{R}}+\mathrm{O}_{2} \longrightarrow \stackrel{\mathrm{OO} \bullet}{\stackrel{\mathrm{C}}{\mathrm{CH}_{2}}-\mathrm{N}} \succ_{\mathrm{R}}^{\mathrm{R}}
\end{aligned}
$$

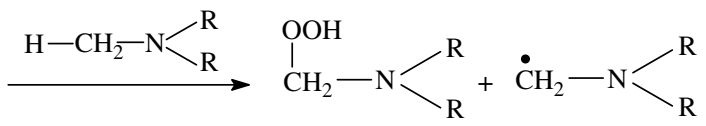

$\mathrm{H}-\mathrm{N} \succ_{\mathrm{R}}^{\mathrm{R}}+{ }^{1} \mathrm{O}_{2} \longrightarrow \cdot \mathrm{N} \succ_{\mathrm{R}}^{\mathrm{R}}+\mathrm{HO}_{2}$<smiles>[R]N[R]</smiles><smiles>[R]N[C@H]1CN([R])[R]1[R]</smiles>

\section{Effects of UV irradiation time on yellowness}

The resin samples for the yellowing study each contained $2.0 \mathrm{wt} \%$ of BPO and $1.0 \mathrm{wt} \%$ of tertiary amine. The samples were subjected to various UV irradiation times and post-cure at $80^{\circ} \mathrm{C}$ and were then evaluated. Figure 7 presents the variation of $\Delta E^{*}{ }_{a b}$ and $\triangle \mathrm{YI}$ as functions of UV irradiation time for resin matrix and resin samples containing various types of tertiary amine. Among all the samples studied, the resin matrix exhibits the highest $\Delta E^{*}{ }_{a b}$ and $\Delta \mathrm{YI}$ since it abounds with phenolic radicals able to react with oxygen. The lowest $\Delta E^{*}{ }_{a b}$ and $\Delta \mathrm{YI}$ are observed for the resin containing 3-amine since there are fewer phenolic radicals to react with oxygen. This indicates that the reactivity of amine with oxygen affects the values of $\Delta E^{*}{ }_{a b}$ and $\Delta \mathrm{YI}$. Angiolini et al. ${ }^{34}$ reported that higher reactivity implies less yellowing and vice 


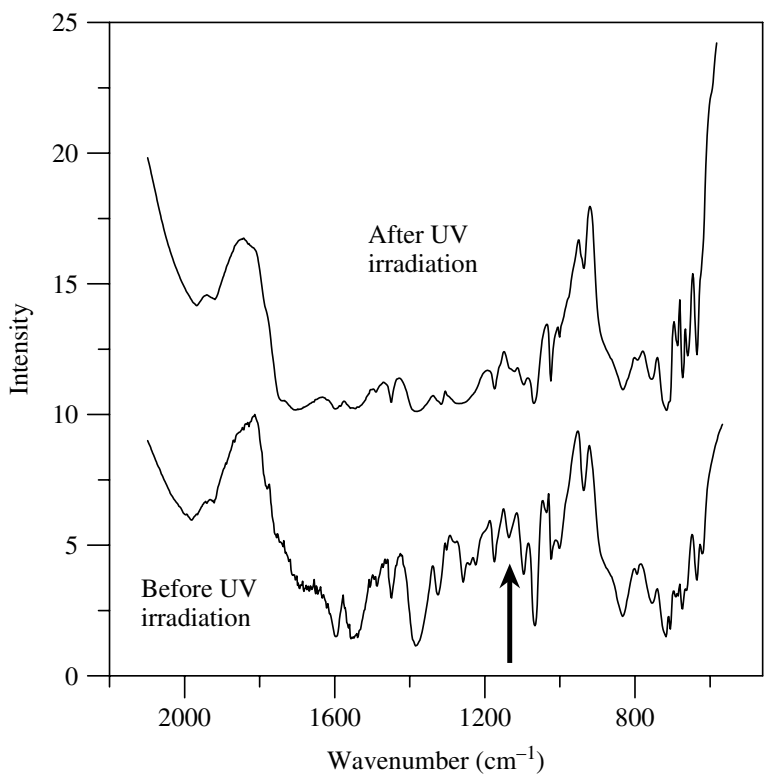

Figure 6. FTIR spectra of 1-amine mixed with BPO before and after UV irradiation.

versa. Our previous study (Chiang TH and Hsieh TE, React Func Polym) found that the reactivity of the amines is in the order 3 -amine $>4$-amine $>1$-amine $>2$-amine $>5$-amine, and therefore the values of $\Delta E^{*}{ }_{a b}$ and $\Delta \mathrm{YI}$ of resins are in the order 3-amine $<4$-amine $<1$-amine $<2$-amine $<5$-amine. The 3 -amine provided the best yellowness improvement, which is attributed to its highest reactivity among all the amines studied in this work and the fact that it has three groups $\left(-\mathrm{CH}_{2} \mathrm{~N}\left(\mathrm{CH}_{3}\right)_{2}\right)$ that can react with singlet oxygen, which can reduce yellowness.

According to the results of our experiment, $10 \mathrm{~min}$ is the most appropriate UV irradiation time, since more free radicals would be induced and react with oxygen to increase yellowing of resins when exposed to excessive UV radiation. Peroxy radicals (ROO`), which are derived from $\mathrm{BPO}$ and photo-initiator in the resins when subjected to excessive UV exposure, might extract hydrogen from 2-amine, 3-amine and 4-amine to form hydroperoxide and $\alpha$-aminoalkyl radicals as depicted by Eqn (17). ${ }^{17}$ The peroxy radicals similarly extract hydrogen from 1 -amine and 5-amine to form hydroperoxide and aminyl radicals in accordance with Eqn (18). ${ }^{35}$ The formation of hydroperoxide thus increases the yellowness of UV-curable epoxide resins.

$$
\begin{aligned}
& \mathrm{ROO}+\mathrm{H}-\mathrm{CH}_{2}-\mathrm{N} \chi_{\mathrm{R}}^{\mathrm{R}} \longrightarrow \mathrm{ROO}^{\delta^{-}}-\cdots-\mathrm{H}^{--} \delta_{-}^{+} \mathrm{CH}_{2}-\mathrm{N}<{ }_{\mathrm{R}}^{\mathrm{R}} \\
& \longrightarrow \mathrm{ROOH}+\stackrel{\mathrm{CH}_{2}}{ }-\mathrm{N}<\frac{\mathrm{R}}{\mathrm{R}}
\end{aligned}
$$

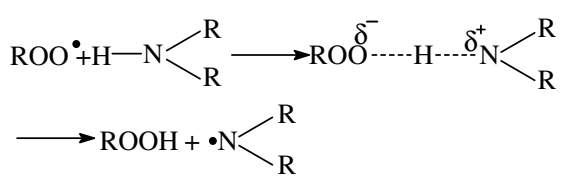

\section{Effects of post-curing temperatures on yellowness}

The UV-curable resins were first irradiated with UV light for $10 \mathrm{~min}$ then underwent post-curing at various temperatures: $80,100,120,140$ and $160^{\circ} \mathrm{C}$. The effects of various post-curing temperatures on $\Delta E^{*}{ }_{a b}$ and $\Delta \mathrm{YI}$ are presented in Figs 8 (a) and (b), respectively. These reveal that, regardless of resin type, yellowing increases with increasing post-curing temperature. Post-curing at a temperature of $160^{\circ} \mathrm{C}$ gave the largest $\Delta E^{*}{ }_{a b}$ and $\Delta \mathrm{YI}$. Apparently high thermal curing temperature accelerates the oxidation of resins and hence increases the yellowness. Peroxy radicals $\left(\mathrm{ROO}^{\circ}\right)$ are formed from $\mathrm{BPO}$ and photoinitiator in the resins when subjected to high postcuring temperature, and one may expect extraction of hydrogen from 2-amine, 3-amine and 4-amine to form hydroperoxide and $\alpha$-aminoalkyl radicals as depicted by Eqn (17). ${ }^{17}$ Further, addition of 1-amine, 2-amine, 3 -amine or 4-amine provides better resistance to yellowing in comparison with addition of 5-amine.

\section{CONCLUSIONS}

Appropriate amounts of BPO in UV-curable epoxide resins will accelerate the crosslinking density; the fastest UV conversion was achieved with a resin sample
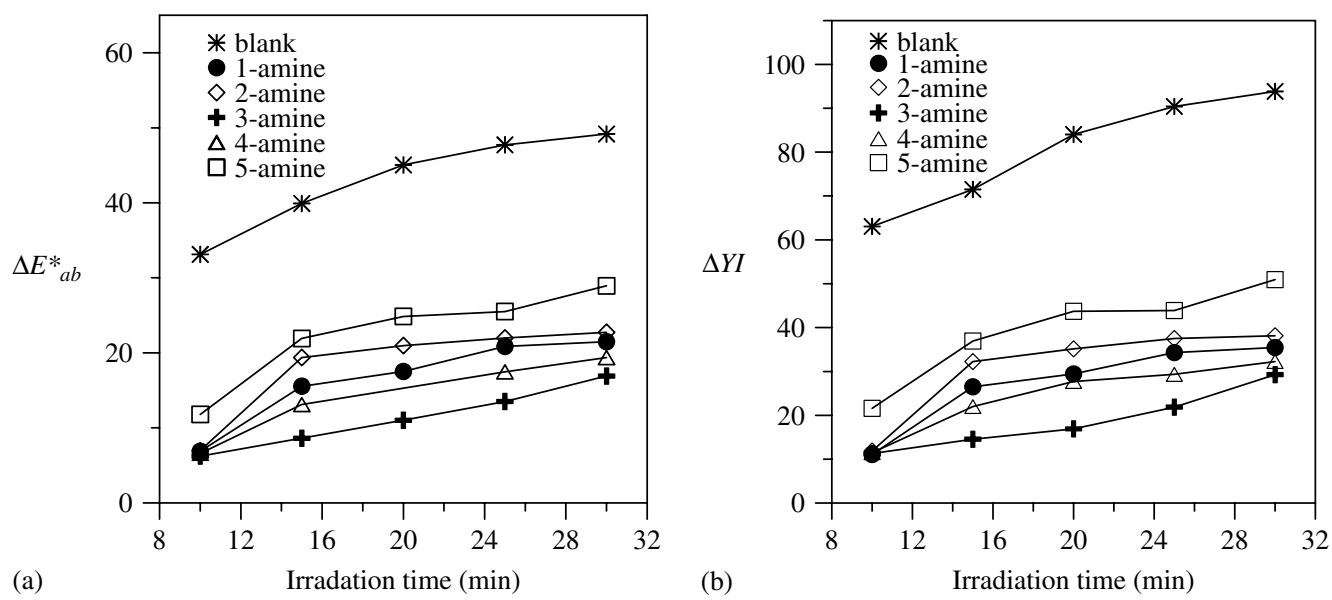

Figure 7. (a) $\Delta E^{*}{ }_{a b}$ and (b) $\Delta \mathrm{YI}$ values of resin samples containing various tertiary amines versus UV irradiation time. 

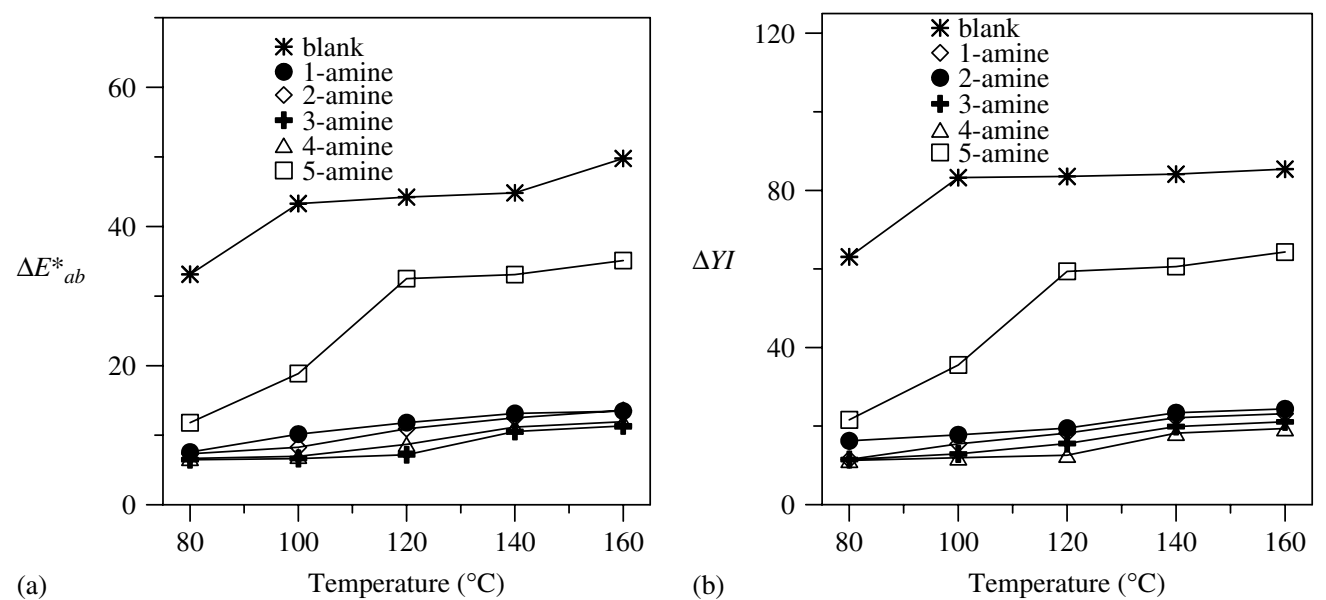

Figure 8. (a) $\Delta E^{*}{ }_{a b}$ and (b) $\Delta \mathrm{YI}$ values of resin samples containing various tertiary amines versus post-curing temperature.

containing $2.0 \mathrm{wt} \% \mathrm{BPO}$, as found by this study. However, phenolic free radicals were also formed from the addition of BPO during UV irradiation by inducing the photolysis of the sulfonium salt photoinitiator and consequently increasing the yellowness of the resins. This work demonstrates that yellowing can be substantially improved by adding imidazole or tertiary amines to the UV-curable epoxide resins. It is found that 2,4,6-tris(dimethylaminomethyl)phenol (designated 3-amine in this work) is the most effective additive, giving values of $\Delta E_{a b}^{*}$ and $\Delta \mathrm{YI}$ of 6.48 and 11.27, respectively; the values for blank resin without the additives are 33.12 and 63.06. Among the amines under study, 3-amine has the highest UV reactivity in the resins, resulting in the photoinitiator producing fewer phenolic radicals to react with oxygen. Yellowness improvement was hence attributed to the good oxygen-scavenging ability of the tertiary amines which effectively inhibits the formation of hydroperoxide in the resins. The maximum amount of amines in the resins has been found to be about $1.0 \mathrm{wt} \%$ and excessive amounts of amines in the resins may retard UV curing. Also, the optimum UV irradiation time and post-curing temperature were found to be $10 \mathrm{~min}$ and $80^{\circ} \mathrm{C}$, respectively, in order to achieve satisfactory yellowing of the UV-curable epoxide resins.

\section{ACKNOWLEDGEMENT}

This work was supported by the MOE program for Promoting Academic Excellence of Universities under grant no. 91-E-FA04-2-4 of the Ministry of Education of the Republic of China.

\section{REFERENCES}

1 Yoshida A, Sugimoto A, Miyadera T and Miyaguchi S, $\mathcal{f}$ Photopolym Sci Technol 14:327 (2001).

2 Lu MH, Weaver MS, Zhou TX, Rothman M, Kwong RC, Hack M et al., f Appl Phys Lett 81:3921 (2002).

3 Burrows PE, Gu G, Forrest SR, Vincenzi EP and Zhou TX, f Appl Phys 87:3080 (2000).

4 Puglisi J and Vigeant F, $\mathcal{F}$ Radiat Curing 7:31 (1980).
5 Hult A, Yuan YY and Ranby B, Polym Degrad Stab 8:241 (1984).

6 Filipescu N and Minn FL, f Am Chem Soc 90:1544 (1968).

7 Decker C and Zahouily K, f Polym Sci Polym Chem 36:2571 (1998).

8 Cho JD, Kim HK, Kim YS and Hong JW, Polym Test 22:633 (2003).

9 Allen NS, Lo D and Salim S, Polym Degrad Stab 45:277 (1994).

10 Crivello JV, Lam JHW, Moore JE and Schroeter SH, $\mathcal{f}$ Radiat Curing 5:2 (1978).

11 Price LN, f Coat Technol 67:27 (1995).

12 Noren CK, $\mathcal{F}$ Coat Technol 72:53 (2000).

13 Dufour P, State-of-the-art and trends in the radiation-curing marker, in Radiation Curing in Polymer Science and Technology: I. Fundamentals and Methods, ed. by Fouassier JP and Rabek JF. Elsevier Applied Science, London, p. 1 (1993).

14 White NJ, Allen NS and Robinson PJ, Post-cured stability of radiation-cured resins in Photopolymerisation and Photoimaging Science and Technology, ed. by Allen NS. Elsevier Applied Science, London, chapter 8 (1989).

15 Millington KR and Kischenbaum L, $\mathcal{f}$ Color Technol 118:6 (2002).

16 Qi Y, Meng X, Yang J, Zeng Z and Chen Y, f Appl Polym Sci 96:846 (2005).

17 Davidson RS, The role of amines in UV curing, in Radiation Curing in Polymer Science and Technology, vol. III, ed. by Fourassier JP and Rabek JF. Elsevier Applied Science, London, pp. 153-176 (1993).

18 Arsu N, Davidson S and Holman R, $\mathcal{f}$ Photochem Photobio A: Chem 87:169 (1995).

19 Allen NS, Lo D and Sailm S, Polym Degrad Stab 45:277 (1994).

20 Allen NS, Marin MC, Wdge M, Davies DW, Garrett J and Jones F, Polym Degrad Stab 73:119 (2001).

21 Fritzsche AK, Holladay HP and Woodcock ML, US Patent 4323454 (1982).

22 Chen Y, Chiu WY and Lin KF, $\mathcal{F}$ Polym Sci Polym Chem 37:3233 (1999).

23 Ooi SK, Cook WD, Simon GP and Such CH, Polymer 41:3639 (2000).

24 Barton JM, Hamerton I, Howlin BJ, Jones JR and Liu S, Polymer 39:1929 (1998).

25 CIE-Colourimetry, Official Recommendations of the International Commission on Illumination. Publication CIE (supplement No 21). Bureau Central de la CIE, Paris, p. 15 (1978).

26 Blum P, Physical Properties Handbook, Chapter 7, ODP Tech. Note, 26, ODP Publications, Texas, (1997).

27 DIN EN 27491, Dentistry: Dental Materials: Determination of Colour Stability of Dental Polymeric Materials. International Standardization Organization, ISO 7491, Beuth, Belgium (1985). 
28 E313-05, Standard Practice for Calculating Yellowness and Whiteness Indices from Instrumentally Measured Color Coordinates; and E308-06, Standard Practice for Computing the Colors of Objects by Using the CIE System (1995).

29 Barson CA and Bevington JC, f Polym Sci Polym Chem 35:2955 (1997).

30 Decker C and Moussa K, F Polym Sci A: Polym Chem 28:3429 (1990).
31 Chiang TH and Hsieh TE, Int 7 Adhes Adhes 26:520 (2006).

32 Chen J and Soucek MD, f Appl Polym Sci 90:2485 (2003).

33 Matysik J, Alia, Bhalu B and Mohanty P, Curr Sci 82:525 (2002).

34 Angiolini L, Caretti D, Carlini C and Lelli N, Polym Adv Technol 4:375 (1993).

35 Hoyle CE and Kim KJ, f Appl Polym Sci 33:2985 (1987). 